\title{
On the Informatization of Tourism Management Guided by the Government
}

\author{
Zhen Li \\ The Engineering \& Technical College of Chengdu University of Technology, Leshan, 614000, P.R. \\ China
}

373622122@qq.com

Keywords: Governmental guidance; Tourism management; Informatization; Measures

\begin{abstract}
The informatization of tourism management guided by the government is that during the information process of a tourist destination, the government should shoulder the responsibilities for overall planning, financing and standardizing management. The paper is to illustrate the terms concerning the informatization of tourism management guided by the government, and based on the analysis of its reasons and problems to propose some effective measures for the government to refer.
\end{abstract}

\section{Introduction}

Tourism is the major economic source for an area rich in tourism resources. And the tourism management has been greatly enhanced due to the increasing requirements of tourists to tourism. It is believed that it has been a trend to informatize tourism management with the prevailing application of computational and network techniques, which should be guided by the government, for it can better fit in with features of tourism products, and meet the demands of tourism enterprises and the requirements of management models for the informatization of tourism management.

\section{About the Informatization of Tourism Management Guided By the Government}

Definition. The informatization of tourism management guided by the government refers to that during the information process of a tourist destination, the government should shoulder the responsibilities for overall planning, financing and standardizing management, including building networks and providing related information services. The purpose is to maximize the economic and social benefits by implementing the informatization strategy to strengthen exchanges and cooperation among interest parties.

Management Models. Generally, there are four management models to implement the informatization of tourism management in terms of overall planning, operation and right of attribution.

The first model is that the government makes the overall planning, and tourism enterprises have the ownership and the right to operate. To be specific, the government is responsible to set up the network platform for tourism information, while tourism enterprises own and operate the platform. The strengths of the model are that it is not difficult to coordinate interest parties in the tourism management owing to the high level of marketization, and helpful to motivate tourism enterprises to improve their efficiency and service quality and cut their costs, for these enterprises have the ownership of and the right to operate the information network platform.

The second model is that the platform is planned and owned by the government but operated by the tourism enterprises. It means that the government is responsible to plan and set up the information network platform and has the ownership of the platform, while the enterprises only have the right to operate it. The model is similar to the following model, for both can cut the costs for the tourism interest parties in information exchanges and coordination, and are beneficial for the parties to improve their efficiency and service quality. Yet, the model has its own advantage, for the government can control and guide the development of the informatization of a tourist destination and finance the 
tourism projects conveniently as the government owns the platform. But, it is reported that for this model, it takes a long time to set up the information network platform, which results in high cost, and it is not good for the enterprises to play their role as the government plays the big part.

The third model is that the platform is planned, operated and owned by the government. It renders low cost in coordination and a short period in setting up the information network platform, for the government is responsible for all the things to informatize tourism management, which ensures the authority of the information and the development of tourism information. But during the whole process, experts are needed to maintain the platform, and then the cost to set up and operate the platform is very high; and now that the enterprises do not participate, it is hard to guarantee their efficiency and service quality.

The fourth model is that the platform is planned, operated and owned by the tourism enterprises. It means that the enterprises, under related policies and regulations, are authorized to plan, set up and operate the information network platform, for which the enterprises shoulder all the responsibilities without the participation and investment of the government. So, with high level of marketization, the interest parties face high costs in coordination and high risks, for without the guidance of the government, it is hard for the parties to go in the right direction and easy to get blind to pursue profits which leads to unfairness and injustice.

\section{Reasons and Problems}

Reasons for the Governmental Guidance in the Informatization of Tourism Management. The great market potential of tourism means great market opportunities. And tourism has been influenced in all aspects by the development of information technology. For example, online travel booking is a new way for people to plan their travelling ahead and has been developing stably. In the following part, the paper is to look into the reasons for the governmental guidance in the informatization of tourism management.

(1) Invisibility and Untransferability of Tourism Products

Invisibility and untransferability of tourism products mean that tourism does not deliver goods and the tourism activities mainly render a flow of people, not a flow of goods. Thus, the demand to e-commerce in tourism is not as high as that in delivering goods.

(2) Simultaneity of Production and Consumption

Simultaneity of production and consumption means that a tourist cannot give a proper remark to a tourism product if he did not really take part in it. That is to say, he estimates a tourism product only through the advertisements and leaflets of tourism enterprises and introductions of friends. But online information can provide a very genuine feeling to a tourist by language, pictures and videos, which can help him get more information about the tourism product.

(3) Diversity in Management Models

There is no obvious difference in tourism contents between China and other countries, but a great difference in who manages the tourism resources. And in China, there are also differences among tourism resources in how to manage. In some area, the tourist office is an administrative function department of the local government, while in other places; the tourist office is just a business sector. The reason for these is due to the development of tourism and people's perception to tourism in different periods in China.

(4) Demands of Tourism Enterprises

As a result of immature tourism market and incomplete management measures, there are only few potential travel websites which survive. Therefore, they need to cooperate with the government to develop. For example "Golden Travel Project" which was launched by National Tourism Administration Information Center by the end of 2000 and later works with Yahtour, has been a great platform for tourism information to be publicized and set a good example for the information building of tourist offices. 
Problems. The informatization of tourism management guided by the government, to some extent, agrees with the present tourism situation and helps the government to play its role in the marketing of a tourist destination. But it is different from the model which really suits the development of tourism under governmental guidance, for it weakens the roles of enterprises and other interest parties as the government tends to take administrative means to help build information of a tourist destination. So it hedges the marketization of tourism network economy, and also gets little support from interest parties. The problems will be discussed in the following:

(1) Problems in Strategy

The potential problems in strategy mainly include: lack of a strong desire to develop tourism sustainably, lack of resources, funds and human resources, the conflict between the short-term plans and the long-term plans of the government, the low efficiency of the government, and corruption in the government. That is why in many countries, the governments try to invite other interest parties to operate to solve these problems.

(2) Problems in Applying DMS

The DMS of tourist destinations is developed by China National Tourism Administration and Yahtour and applied in the local areas with governmental orders. By this, it is very helpful to manage and set up standards to share tourism information, but it is also hard to build a marketing system for a destination according to its realities, for which the interest parties do not advocate or support. Meanwhile, it is difficult to improve the information technology applied in tourism by market competition for Yahtour has the edge over other technology providers as it gets the policy and financial support from the government.

(3) Problems in Availability and Contents of Tourism Information

The target of DMS is to provide information and support for the interest parties to make strategies. Therefore, the information provided by DMS should be timely so that the information can play its role. Meanwhile, the provided information must take the interests of parties into consideration and meet the demands of the tourism industry. The information for the DMS mainly is collected and processed by the local tourist offices and then handed over to the higher authorities to summarize, select and publicize, which means the information is passed slowly and is not updated on time. Besides, the information collected by tourist offices is usually not testified by the market so that DMS does not meet the demands of the market and requirements of enterprises and other parties.

(4) Problems in the Profit Model

The present DMS is developed and established mainly by the government, so it does not have its own channel to get stable profits. But the operation, updates of hardware and software and developments of new application functions requires continuous funds, which means that only governmental investments are not enough for DMS and also impose burdens to the government's finance. Besides, DMS guided by the government emphasizes on the building of the system, not on providing services and input of manpower. So it is short of experts in tourism and information technology to be in charge of its operation, and for most of local tourism offices, they do not have a specific department to do this, but several departments to handle. It is to say, DMS is mainly for political, not commercial purpose.

As mentioned above, during the information process of tourism, governmental guidance should take the realities of tourism into consideration, and play an active role in it to lessen or avoid the negative factors. Only by these can DMS work well in the marketing of tourist destinations.

\section{Measures for the Implementation}

To Strengthen the Guidance of the Government. It is believed that the government has a great influence on the development of informatization and help cut the cost. Some experts support that the government should take the leading role and play its role in the process of informatization, such as $\mathrm{Hu}$ Xiqin and Zhang Yugai. But it is worth noting that the role of the government is to guide, not to force. The final decision should be made by enterprises according to their own situations, for the enterprises 
which are entitled to the right of making decisions will employ their resources in the light of optimal allocation, while pursuing the maximization of profits, which is rational in economy and also conform to the rules that economy grows.

To Strengthen the Investment of the Government. The investment of the government mainly refer to two parts: 1) direct financial investment, which means the government has the ownership of tourism management information, the tourism information has the feature of publicity and the enterprises are unwilling to invest money. So that is why the government should fund directly to ensure the informatization of tourism management. 2) policy input, which means the government should help enterprises participate in the information process without violating economic rules, for on one hand, although the government plays a leading role in the information process, it cannot take all the responsibilities; on the other hand, it is the enterprises that determine the development of the informatization of tourism management and meet the demands of the tourism market by optimal allocation.

To Support the Development of Information Technology in Tourism. The government should support the development of information technology in tourism to play its leading role. The authorities should formulate a development framework for tourism enterprises and network companies to apply the new information technology. It also should encourage tourism enterprises to market online or authorize network companies to market its tourism products with the security measures provided by banks and network service providers, such as Yahtour. Meanwhile, local tourist offices should take responsibility to guide tourism to go in the right direction.

To Integrate the Informatized Tourism Resources. Although tourism resources are abundant, even for a tourist destination, the resources are scattered and low in sharing and developing, which is a great waste. The informatization of tourism management guided by the government requires the government to pull together all information resources in tourism for the information network platform, and set up and operate the platform under the policy of unified planning and grading construction, and the enterprises to be in charge of the specific operations to enhance the utilization of resources.

To Have a Clear Perception to Its Functions. During the information process, the government should have a clear perception to its functions. The planning for the tourism information should focus on how to highlight the image and tourism band of a local tourist destination and how to present the scenic spots of the places, enterprises, tourism products and so on. Therefore, in the process, the government should play the role of guidance, integrate all the resources, and encourage the enterprises, association, investors to participate while listening to their suggestions. For the profit model, the government should invest money with enterprises in a proper way to coordinate the profits of the whole industry and enterprises. So, the function of the government is the organizer, participant and coordinator to the information building of a tourist destination.

\section{References}

[1] Chen Shuo. Probe into the construction of urban tourism informatization-Taking the tourism informatization construction in Hangzhou city as an example. East china economic management, 2005. 19(03).

[2] Lin Feng. Tourism operation strategy. Tourism Education Press, 2005.

[3] CHEN Shuo. Research on the information of tourism destination under the government's leading strategy, East China Normal University, 2006.

[4] Gong xiao long. Discussion on the information of Tourism Management under the guidance of the government. China Management Informatization, 2015, 2.

[5] Fu Xi san. Discussion on the information of Tourism Management under the guidance of the government. Commercial Times, 2009, 7. 